\title{
Reflexões sócio-históricas sobre a cultura do design: do final do século XVIII ao início da Bauhaus
}

Socio-historical reflections on the culture of design: from the end of the XVIII century to the beginning of the Bauhaus

BELCHIOR, Camilo; Mestre; Universidade do Estado de Minas Gerais

camilo.belchior@uemg.br

REZENDE, Edson José Carpintero; Doutor; Universidade do Estado de Minas Gerais

edson.carpintero@uemg.br

\section{Resumo}

A relação do homem com os objetos de consumo é mais do que uma relação de posse. Em algumas situações, características diferenciais de qualidade, estética e técnica dos produtos ficam em segundo plano e as experiências e sensações que eles produzem tornam-se centrais. Em certas ocasiões, o designer é mais que um criador de produtos, torna-se um materializador de ideias, pois através da linguagem de sua criação, pode criar e traduzir conceitos, que ultrapassam o valor monetário dos objetos, gerando um valor simbólico, ou seja, algo que faça sentido para as pessoas. Neste contexto, estes conceitos, signos da ideação humana, são designados pela sociedade aos artefatos, que acompanham o dia a dia das pessoas, registrando na memória social os indícios de uma cultura. A proposta deste artigo é refletir sobre a formação de uma cultura específica do design, através dos registros que os sistemas sígnicos dos artefatos propiciam.

Palavras Chave: Design; Cultura; Artefato.

\begin{abstract}
The relation of man to objects of consumption is more than a relation of possession. In certain situations, the quality, aesthetic and technical differential of products is left behind and the most important is the experiences and sensations they produce. At times, the designer is more than a creator of products, he is also a materializer of desires, because through his language of creation, he can implant concepts, that surpass the monetary value of the objects, generating a sign value, something that makes sense for people. In this context, these concepts, signs of human ideation, are designated by society to the artifacts, which accompany the day to day of the people, recording these memories. The proposal of this article, part of a research of doctoral thesis is to reflect on the formation of a specific culture of the design, through the registries that the sign systems of the artifacts propitiates.
\end{abstract}

Keywords: Design; Culture; Artifact. 


\section{Introdução}

É perceptível que o design vem ocupando um lugar de destaque nos movimentos históricos, sejam eles sociais, econômicos ou culturais, é possível relacionar as mudanças da área com o comportamento dos indivíduos de uma sociedade. Entender esta ligação, como ela surge e os elementos que a controlam, pode auxiliar os profissionais de design a compreenderem que os sentimentos de pertença de uma comunidade, seus costumes, o modo de vida, hábitos e desejos, que por sua vez, resultam em necessidades que vão impulsionar a produção de artefatos. Buscouse criar um resumo de estudo articulado de autores da área do design para compreender alguns movimentos históricos e seu impacto na construção de uma cultura do design.

Esses artefatos poderão conter de significados que carregam a historicidade das pessoas ou de grupos sociais.

Para tornar-se objeto de consumo é preciso que o objeto se torne signo, quer dizer, exterior de alguma forma a relação da qual apenas significa - portanto arbitrário e não coerente com esta relação concreta, mas adquirindo coerência e consequentemente sentido em uma relação abstrata e sistemática com todos os outros objetos-signos. É então que ele se 'personaliza', que entra na série, etc.: é consumido - jamais na sua materialidade, mas na sua diferença (BAUDRILLARD, 2006, p. 207).

Moles (1981) dialoga com Baudrillard ao afirmar que os objetos são portadores de signos e, portanto, valores da vida cotidiana. Mudam os valores da vida - mudam os signos - mudam os objetos, ou seja, a significação que se dá às coisas está diretamente relacionada ao repertório de vida que as pessoas acumulam, e às variáveis que perpassam a relação homem/objeto. Para Zurlo (2006), o design se ocupa em dar sentido ao sistema dos objetos que circunda as pessoas, ou seja, cada ser humano vive os objetos, sustenta-os com a própria energia psíquica, vê-os como parte de si, da própria vivência. Para o autor, na sociedade contemporânea, essa extensão de si dá vida psíquica aos objetos e também às relações das pessoas, contribuindo também para a relevância do papel de quem cria a forma, ou seja, o design. Zurlo ainda afirma que a forma, hoje, não é mais somente a manifestação tangível de um objeto com alguma função, mas o canal de acesso a um sistema de significados que vai além da sua estrutura física. Portanto, acredita-se que para entender os mecanismos de ação dos sistemas sígnicos, antes, deve-se buscar compreender de onde são originados.

No livro Ideologia e Cultura Moderna, Thompson (2011) diz que na literatura das ciências sociais, o estudo das formas simbólicas geralmente tem sido feito sob a rubrica do conceito de cultura. $O$ autor acredita que embora possa haver pouco consenso em relação ao significado do conceito em si, alguns analistas como: Piepe, Emerson, Lannon citados por Thompson (2011, p. 420) concordam que o estudo dos fenômenos culturais é uma preocupação de importância central para as ciências sociais como um todo. Isto porque a vida social não é, simplesmente, uma questão de objetos e fatos que ocorrem como fenômenos de um mundo natural: ela é, também, uma questão de ações e expressões significativas, de manifestações verbais. $O$ autor ressalta que símbolos, textos e artefatos de vários tipos, e de sujeitos que se expressam através desses artefatos, procuram entender a si mesmos e aos outros pela interpretação das expressões que produzem e recebem. Num sentido mais amplo, o autor acredita que o estudo dos fenômenos culturais pode ser pensado como o estudo do mundo sócio-histórico constituído como um campo de significados. 


\section{Como surgiram as primeiras pesquisas sobre cultura?}

Acredita-se que o termo cultura tenha surgido em meados de 1871, uma derivação dos termos Kultur e Civilization, mas foi o antropólogo britânico Edward Tylor que sintetizou o termo para o inglês Culture, que abrange num só vocabulário o entendimento que compreende todas as realizações humanas (LARAIA, 2001). No entendimento de Tylor a cultura seria um fenômeno natural e passível de ser analisado sistematicamente com o objetivo de formular leis que pudessem explicar a sua gênese, sua transmissão, formalizando uma ideia bastante recorrente entre os pensadores da época. Antes dele, em 1690 o filósofo inglês John Locke citado por Laraia (2001, p. 25) demonstrava em seu ensaio que a mente humana seria uma caixa vazia no momento do nascimento, sendo dotada de capacidade ilimitada de adquirir conhecimento, através do processo chamado nos dias de hoje de endoculturação ${ }^{1}$. Completando o pensamento de Tylor, meio século depois, o pensador francês Jacques Turgot citado por Laraia (2001) salientava em seu discurso que:

Possuidor de um tesouro de signos que tem a faculdade de multiplicar infinitamente, o homem é capaz de assegurar a retenção de suas ideias eruditas, comunicá-las para outros homens e transmiti-las para os seus descendentes como uma herança sempre crescente. (LARAIA, 2001, p. 26).

Uma reação ao pensamento evolucionista de Tylor apareceu a partir da publicação de um artigo do antropólogo Franz Uri Boas, citado por Laraia (2001, p. 26), em 1896, intitulado: The Limitation of the Comparative Method of Anthropology, onde o autor atribuiu à antropologia a função de reorganizar a história de vários povos e comparar suas vidas sociais. É a partir deste pensamento que Franz Uri Boas inicia na sociedade a aceitação do evolucionismo². Na sequência, vários pensadores e antropólogos começaram a desenvolver seus conceitos de cultura, como: Karl Maximilian Weber quando diz que o "O homem é um animal que vive preso a uma teia de significados por ele mesmo criada" (GEERTZ, 2008, p. 4); David Schneider: "Cultura é um sistema de símbolos e significados" (LARAIA, 2001, p. 63); mais tarde, em 1973, Geertz, imbuído destes mesmos pensamentos, sugere em seu livro The Interpretation of Cultures, que a teia de significados que criamos e todo seu processo de análise sejam chamados de cultura e que é missão do antropólogo desvendar estes significados e sugerir interpretações (GEERTZ, 2008). Como um sistema de signos é passível de interpretações, conforme Geertz nos fala:

A cultura não é um poder, algo ao qual podem ser atribuídos casualmente os acontecimentos sociais, os comportamentos, as instituições ou os processos; ela é um contexto, algo dentro do qual eles (os símbolos) podem ser descritos de forma inteligível, isto é, descritos com densidade (GEERTZ, 2008, p. 10).

Seguindo este pensamento de Geertz, pode-se repensar o conceito de Tylor, que afirma que a cultura é um fenômeno natural, e ao invés disso, deduzir que a cultura é um fenômeno social, cuja origem, manutenção e transmissão estão sob única e exclusiva responsabilidade dos agentes sociais, ou seja, as pessoas. Percebe-se que a existência de tantas definições acerca da cultura, surgidas ao longo da história humana, ora discordam, ora se complementam. Neste artigo, como referencial, adotou-se a definição de Geertz, que foi baseado no conceito de Max Weber:

O homem é um animal amarrado a teias de significados que ele mesmo teceu, assumo a

\footnotetext{
${ }^{1}$ É o processo permanente de aprendizagem de uma cultura que se inicia com assimilação de valores e experiências a partir do nascimento de um indivíduo e que se completa com a morte. Este processo de aprendizagem é permanente, desde a infância até à idade adulta de um indivíduo.

${ }^{2}$ Doutrina segundo a qual toda a cultura de uma sociedade é resultado constante de um processo evolutivo.
} 
cultura como sendo essas teias e sua análise. Portanto, não como uma ciência experimental em base de leis, mas como uma ciência interpretativa, à procura do significado (GEERTZ, 2008, p. 4).

Corroborando com Weber, Thompson considera que:

Ao analisar a cultura, entramos em emaranhadas camadas de significados, descrevendo e redescrevendo ações e expressões que são já significativas para os próprios indivíduos que estão produzindo, percebendo e interpretando essas ações e expressões no curso da vida diária. (THOMPSON, 2011, p. 175).

A concepção simbólica, portanto, confere sentido às expressões linguísticas e também a construções não linguísticas como ações, obras de arte e objetos materiais de diversos tipos. Thompson (2011, p. 193) acrescenta que a inserção destas formas simbólicas em contextos sociais, implica que, além de serem expressões de um sujeito, são geralmente produzidas por agentes situados dentro de um contexto sócio-histórico específico e dotados de recursos e capacidades de vários tipos. $\mathrm{O}$ autor ainda salienta que as formas simbólicas carregam os traços, de diferentes maneiras, das condições sociais de sua produção.

As formas simbólicas são construções significativas que são interpretadas e compreendidas pelas pessoas que as produzem e recebem, mas elas são também construções que são estruturadas de maneiras definidas e que estão inseridas em condições sociais e históricas específicas. (THOMPSON, 2011, p. 365).

\section{Uma investigação Sócio-histórica}

Para uma reflexão histórica acerca da relação do homem com os artefatos, fator primordial na construção de uma cultura do design, propõe-se iniciar o percurso desta investigação no século XVIII, mais precisamente na Inglaterra, onde boa parte dos acontecimentos que marcaram a organização industrial, precursora do design, surgiu. Neste período, a maioria dos britânicos ganhava a vida trabalhando na terra, com a agricultura, em que as variações do subsolo e do clima faziam oscilar tanto as condições de vida, como de trabalho das pessoas, que em sua maioria era manual.

De fato, exceto em algumas áreas comerciais e industriais bastante desenvolvidas, seria muito difícil encontrar um grande Estado europeu no qual ao menos quatro de cada cinco habitantes não fossem camponeses. E até mesmo na própria Inglaterra, a população urbana só veio a ultrapassar a população rural pela primeira vez em 1851. (HOBSBAWM, 2016, p. 33).

Em grande parte da Grã-Bretanha a produção têxtil foi um dos ramos mais proeminentes e antigos da economia camponesa. A lã de carneiro forneceu durante um bom tempo matéria prima para uma atividade que teve relevância econômica logo após a agricultura, levando-se em conta a quantidade de trabalhadores empregados e o volume que seu comércio representou. $O$ governo inglês deu bastante importância a este tipo de produção, o que é observável quando se analisam algumas medidas que foram adotadas na época, como dificultar ao máximo a exportação da lã bruta; permitir a emigração de trabalhadores especializados e conter a importação de produtos que pudessem competir com os tecidos de lã dentro do mercado interno (ASHTON, 1977). Nesta época, as pessoas na época eram encorajadas a se vestirem apenas com tecidos ingleses e nem mesmo enterros eram permitidos com mortos usando outro tipo de tecido que não fosse lã. Em pouco mais de 100 anos, a partir de 1750, com o desenvolvimento dos processos agrícolas percebeu-se que a 
produção de tecido de algodão era mais rápida e mais rentável, levando o país a um grande desenvolvimento econômico.

\begin{abstract}
A cidade provinciana ainda pertencia essencialmente à sociedade e à economia do campo. Além de se refestelar sobre os camponeses vizinhos, ocupava-se (relativamente com poucas exceções) de muito pouco mais, exceto de lavar sua própria roupa. Suas classes média e profissional eram constituídas pelos negociantes de trigo e de gado, os processadores de produtos agrícolas, os advogados e tabeliães que manipulavam os assuntos relativos ao patrimônio dos nobres ou os intermináveis litígios que são parte integrante da vida em comunidades proprietárias de terras, os empresários mercantis que exploravam os empréstimos aos fiandeiros e tecelões dos campos, e, por fim, os mais respeitáveis representantes do governo, o nobre e a Igreja. Seus artesões e lojistas asseguravam as provisões aos camponeses e aos citadinos que viviam à custa dos camponeses (HOBSBAWM, 2016, p. 35).
\end{abstract}

$\mathrm{Na}$ época, muitas pessoas com domínio de técnicas variadas, passaram a se reunir em pequenos grupos com o objetivo de trocar experiências e ideias sobre inovações. Outros, tomavam iniciativas próprias, como o caso do comerciante inglês Thomas Lombe, que montou uma autêntica fábrica com cerca de 300 funcionários no condado de Derbyshire (próximo à região do Rio Derwent) depois que seu irmão, John Lombe, trouxe da Itália vários desenhos de máquinas para a indústria têxtil - especula-se que este tenha sido um dos primeiros atos de espionagem industrial. Posteriormente, uma série de outras iniciativas parecidas, ou seja, fábricas de tecidos começaram a surgir nas proximidades e em outras localidades da Inglaterra (ASHTON, 1977, p. 52).

A partir de 1760 uma quantidade expressiva de máquinas movidas a vapor surgiu na Inglaterra, promovendo inovações industriais nas áreas agrícolas, transporte, indústria de um modo geral e comércio, refletindo nas finanças do país. Sob o ponto de vista do design, percebe-se que a atuação de alguns técnicos da época passava pelo processo básico que é comum ao designer dos dias atuais, ou seja, criar, conceber, desenhar, produzir, montar, prototipar e testar, ainda que fossem máquinas para produzir outras máquinas. Estes poderiam são os primeiros sinais da construção de uma cultura do design, ou seja, a produção de artefatos impregnados de intencionalidade humana, geradora de significados, passíveis de interpretações e reinterpretações contínuas (ASHTON, 1977, p. 54).

De acordo com Thompson (2011), é possível elaborar uma concepção estrutural da cultura, através da discussão de cinco características das formas simbólicas, descritas como aspectos: Intencionais, convencionais, estruturais, referenciais e contextuais. De acordo com o autor, os aspectos intencional, convencional, estrutural e referencial estão diretamente relacionados com o que é comumente entendido pelo termo "significação". Já o aspecto contextual está relacionado às questões de interpretação. Para Thompson (2011) todo o processo de produção, distribuição e recepção das formas simbólicas dependem dos contextos ou instituições que as geram.

$\mathrm{Na}$ literatura de Forty (2007, p. 25-26), dois apontamentos poderiam exemplificar as ideias de Thompson (2011):

a) Para popularizar o conhecimento científico da época, o médico e cientista Erasmus Darwin não usou a linguagem da ciência, mas escreveu um poema épico clássico, The Botanic Garden (FIG. 1), publicado em duas partes, em 1789 e 1791, que se tornou um grande sucesso popular na época. Darwin descrevia deliberadamente a ciência com metáforas e imagens clássicas: o poder da máquina a vapor, por exemplo, era descrito numa longa e elaborada metáfora que equivalia à força de Hércules. Se observado hoje, o resultado poderia parecer despropositado e artificial, mas a 
popularidade do poema na época mostra que se tratava de uma maneira aceitável de comunicar ideias e conhecimentos progressistas.

b) Quando procurou anunciar suas habilidades técnicas de ceramista, Wedgwood decidiu reproduzir o vaso Portland (FIG. 1), a famosa peça romana de camafeu ${ }^{3}$ adquirida pelo duque de Portland em 1786. O objetivo das reproduções serviria, não apenas provar que eram tão boas quanto os originais, mas também demonstrar a sofisticação das técnicas de produção correntes e sua superioridade em relação ao que qualquer design novo e original pudesse fazer.

Figura 1 - The Botanic Garden e cópia do vaso Portland, Josiah Wedgwood
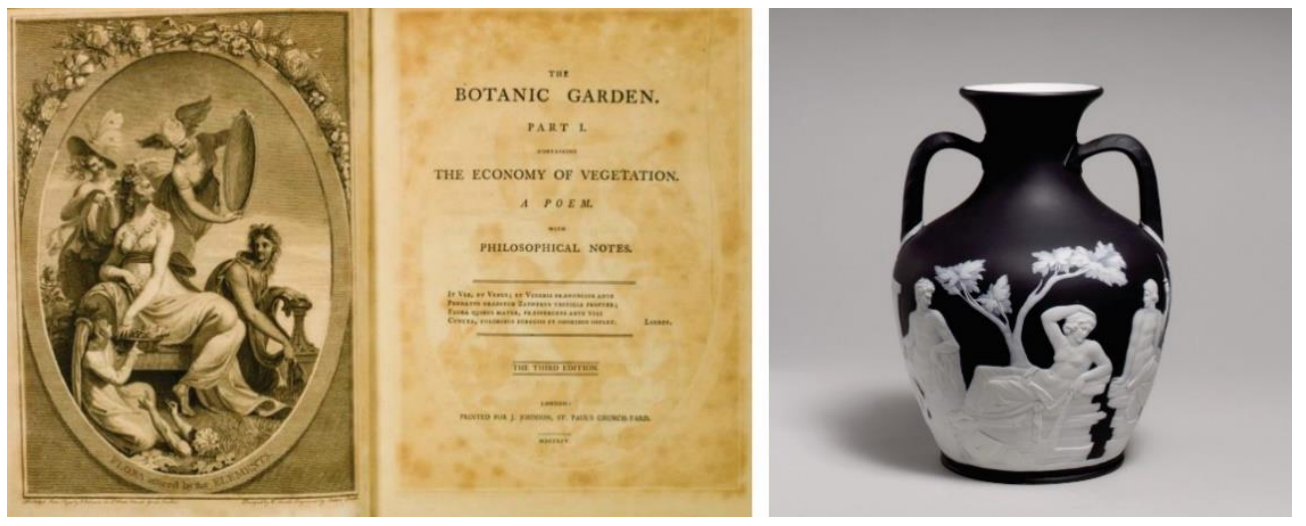

Fonte: Pinterest

No exemplo à esquerda (FIG. 1) percebe-se uma forma simbólica a partir da mitologia de Hércules que representava, para o contexto histórico da sociedade da época, algo que possivelmente fazia parte do repertório de vida dos cidadãos da época, possibilitando o entendimento do signo relacionado à "força", relacionado neste caso com a criação das máquinas a vapor. Já no exemplo à direita (FIG. 1), Wedgwood quis demonstrar através de uma relação simbólica que suas habilidades como ceramista eram capazes de gerar um produto à altura de um artefato que poderia ser considerado pela sociedade como um ícone máximo da arte humana. Para a construção de uma cultura do design, pode-se considerar relevante o trabalho de Josiah Wedgwood, um artesão ceramista que resolveu apostar no desenvolvimento do seu negócio e estruturou uma indústria para a produção de vasos, pratos, e outros utensílios. Um dos fatores que propiciou o crescimento do seu negócio foi o aumento da popularidade do hábito de tomar chá no país, que exigia o uso da cerâmica no lugar de um vasilhame de metal, por se tratar de uma bebida quente. Além disso, outras razões que tornaram Wedgwood o mais bem-sucedido fabricante da época foram: a racionalização de seus métodos de produção, suas criativas técnicas de marketing e principalmente sua atenção com os produtos fabricados, características que podem ser relacionadas à profissão dos designers, na atualidade. É possível que o aspecto contextual dos artefatos produzidos por Wedgwood, sejam percebidos como formas simbólicas, de acordo com a orientação de Thompson (2011):

A inserção destas em contextos sociais implica que, além de serem expressões de um sujeito, essas formas são, geralmente, produzidas por agentes situados dentro de um

\footnotetext{
${ }^{3}$ Material cerâmico semiprecioso que possui duas camadas de tonalidades diferentes da mesma cor ou de cores diferentes, onde é possível esculpir uma figura em alto-relevo, tornando visível a camada inferior.
} 
contexto sócio-histórico específico e dotados de recursos e capacidades de vários tipos; as formas simbólicas podem carregar os traços, de diferentes maneiras, das condições sociais de sua produção. Outra consequência de sua inserção contextual consiste em que elas são, frequentemente, objeto de complexos processos de valorização, avaliação e conflito. São constantemente valorizadas e avaliadas, aplaudidas e contestadas pelos indivíduos que as produzem e recebem. (THOMPSON, 2011, p. 193).

Thompson ainda diz que dentro de qualquer campo de interação, os indivíduos baseiam-se em três diferentes tipos de recursos que ele chama de "capital": o capital econômico, o capital cultural e o capital simbólico. É possível que, no trabalho de Wedgwood, a utilização do capital econômico tenha ocorrido através do investimento que ele fez em sua fábrica e nos seus processos de produção, ampliando suas instalações e contratando mão de obra especializada; no capital simbólico, ao buscar inserir em seus artefatos significados relacionados a elementos que já possuíssem algum tipo de valor para a sociedade da época; e o capital cultural se evidencia quando Wedgwood se apropria do neoclassicismo para influenciar sua produção.

O interesse pelas antiguidades clássicas fazia parte do movimento neoclássico, que se desenvolveu nas décadas de 1750 e 1760 e dominou o gosto europeu no final do século XVIII. O neoclassicismo pretendia recuperar para a arte e o design a pureza de forma e expressão que julgava faltar no estilo rococó da primeira metade do século XVIII e que era identificada naquilo que a Grécia e Roma haviam produzido (FORTY, 2007, p. 24).

Em 1769 Wedgwood se associa a seu amigo Thomas Bentley, um negociante da cidade de Liverpool. Bentley era um homem cult o e esta característica foi levada à indústria Wedgwood, criando um diferencial que marcaria sua trajetória. O resultado deste processo, na época, elevou os produtos da indústria Wedgwood ao patamar de líder vanguardista do bom gosto. Neste caso, percebe-se características da arte influenciando no percurso da criação de novos produtos, situação reconhecida dentro do processo do design. Um elemento que se pode acrescentar para a construção da cultura do design. O trabalho de Josiah Wedgwood perdura por gerações. Seu legado, hoje propriedade do grupo finlandês Fiskars ${ }^{4}$, continua sendo sinônimo de bom gosto e tradição no que diz respeito a produtos cerâmicos.

A partir de 1790, percebe-se na Europa um aumento vertiginoso da produção de ferro, o que levou à substituição da madeira por este metal em uma série de produtos e principalmente edificações, como o Palácio de Cristal, uma construção gigantesca desenhada por Joseph Paxton e instalada no Hyde Park (Inglaterra) para abrigar grandes eventos e exposições, como foi o caso da Exposição Universal de Londres em 1851. Para além da inovação em termos de construção, o Palácio de Cristal representou também o que havia de mais moderno em termos de produção industrial. A exposição universal foi o primeiro evento realizado no Palácio de Cristal tendo a participação de um grupo de comerciantes liderados por Henry Cole, que desenvolveu a ideia da grande exposição onde produtos industrializados provenientes de várias nações ao redor do mundo seriam expostos. Foi a primeira vez na história da humanidade que profissionais das Artes, Ciências e Comércio puderam se reunir em um único espaço para discutir os avanços tecnológicos mundiais (PEVSNER, 2001).

O Palácio de Cristal é considerado por muitos historiadores, como: Argan (2014), Hobsbawm (2016) e Pevsner (2001) como uma das edificações com mais desenvolvimento tecnológico da época, considerando construções baseadas na utilização inteligente de materiais. Sua construção

\footnotetext{
${ }^{4}$ Fiskars tornou-se uma empresa líder em bens de consumo com marcas mundialmente reconhecidas, incluindo Fiskars, littala, Gerber, Wedgwood e Waterford.
} 
foi estruturada em elementos pré-fabricados de aço e vidro, algo inovador para época. Por ter absorvido um terço da produção de vidro da Inglaterra provocou a extinção do imposto referente ao material. Sua criação trouxe para o mercado da construção civil o entendimento de que dois materiais que até então eram utilizados apenas como elemento estrutural (ferro) e de acabamento (vidro), poderiam ser também utilizados em toda a construção de uma obra, sendo assimilados e percebidos de uma forma diferente neste contexto, com outro valor simbólico.

Alguns autores e pesquisadores de temas relacionados ao design, como Burdek (2006), Bonsiepe (2011) e Verganti (2012), consideram que o profissional especialista nesta área é capaz de manipular os processos de criação de forma inovadora, utilizando a tecnologia disponível para criar e desenvolver projetos que realmente possam suprir as necessidades e desejos da sociedade em geral.

Avançando na história do design, depara-se com um momento onde o avanço industrial começou a preocupar artistas e pensadores e provocou reflexões acerca da qualidade estética dos artefatos produzidos na época. As principais preocupações seriam o mau gosto dos produtos até então produzidos, a poluição ambiental e a desumanização progressiva das condições de trabalho. Este repúdio incentivou a defesa de uma produção qualitativa artesanal no lugar de uma produção industrial.

Forty (2007) aponta que o que os críticos da época não conseguiam ver ou se recusavam a reconhecer que era que a própria produção capitalista, causa da necessidade do trabalho especializado de design, sendo ao mesmo tempo responsável pela deterioração da sua qualidade, mas que os artistas, arquitetos e intelectuais da época, que se envolveram na reforma do design, estavam muito associados à riqueza industrial e comercial para ousarem se aventurar numa linha radical de crítica.

Posteriormente, surge a figura de William Morris, um personagem importante no processo de evolução do design, pois discutia o tema em relação à natureza, à arquitetura e os ambientes sociais, estabelecendo, desta forma, uma relação interdisciplinar entre a arte e vários segmentos da experiência humana. Seu traço único, desprovido de poluição visual, mantinha harmonia na utilização de cores. O cuidado e zelo podiam ser percebidos nos projetos de Morris. Acredita-se que uma de suas obras mais expressivas tenha sido o projeto da Red House, a edificação da sua própria casa, totalmente mobiliada e decorada por ele próprio. Durante seu processo de desenvolvimento profissional, Morris estabeleceu alguns parâmetros que ordenavam a sua produção: 1. Pensar no material que seria utilizado, priorizando a qualidade e a sua nobreza (madeiras de lei); 2 . Considerar as questões de uso, dando vital importância à função do que era criado; 3. Prever todo processo de produção; 4. Alinhar este processo de produção com o ferramental utilizado. Nesta etapa, também é possível perceber os traços iniciais de critérios básicos do design contemporâneo. A paixão de Morris pela Idade Média era notória, o que levou a sua definição de arte como: "a expressão pelo homem de seu prazer no trabalho", então surge seu envolvimento com o movimento Arts \& Crafts, liderando ações que defendiam o artesanato como uma alternativa possível à industrialização da produção em massa e o fim da distinção percebida entre os artesãos e os artistas, imprimindo na sua produção o traço artesão-artista, que nos dias atuais, pode-se reconhecer como origem da classe dos designers (FORTY, 2007).

Hobsbawm (2016) aponta que durante as décadas do século XVIII a sociedade burguesa estava confiante e orgulhosa de seu sucesso e que em nenhum outro campo da vida humana isso 
era mais evidente que o avanço do conhecimento, das "ciências". O autor salienta que homens cultos do período não estavam apenas orgulhosos de suas ciências, mas preparados para subordinar todas as outras formas de atividade intelectual a elas, e questiona: "Mas o que representava essa força elementar no período, senão o capitalismo e o mundo feito pela e para a burguesia?" Hobsbawm (2016, p. 378-379). Ao refletir sobre esta questão, destaca-se o trabalho de outra expressão dos primórdios do design mundial, o trabalho de Michael Thonet, um curioso e estudioso sobre técnicas de marcenaria, um exemplo clássico do processo de evolução industrial focada no capitalismo, que reinava em toda Europa. Em 1818 Thonet instalou uma pequena fábrica de móveis na cidade de Boppard, na margem oeste do Rio Reno na Alemanha. Mas foi durante as décadas de 1830/50 que Thonet conseguiu um feito notável: depois de muitos testes e experimentos, descobriu como seria possível usar um processo industrial para curvar madeiras. Deste processo nasce a famosa cadeira no 14 (FIG. 2), hoje chamada de 214, criação que encantou a classe burguesa num primeiro momento, permitindo, posteriormente, sua produção e venda em massa por ser um produto relativamente acessível, sendo a cadeira mais vendida na história do mobiliário mundial.

Figura 2 - Michael Thonet; Cadeira no 14; Embalagem com 36 cadeiras desmontadas

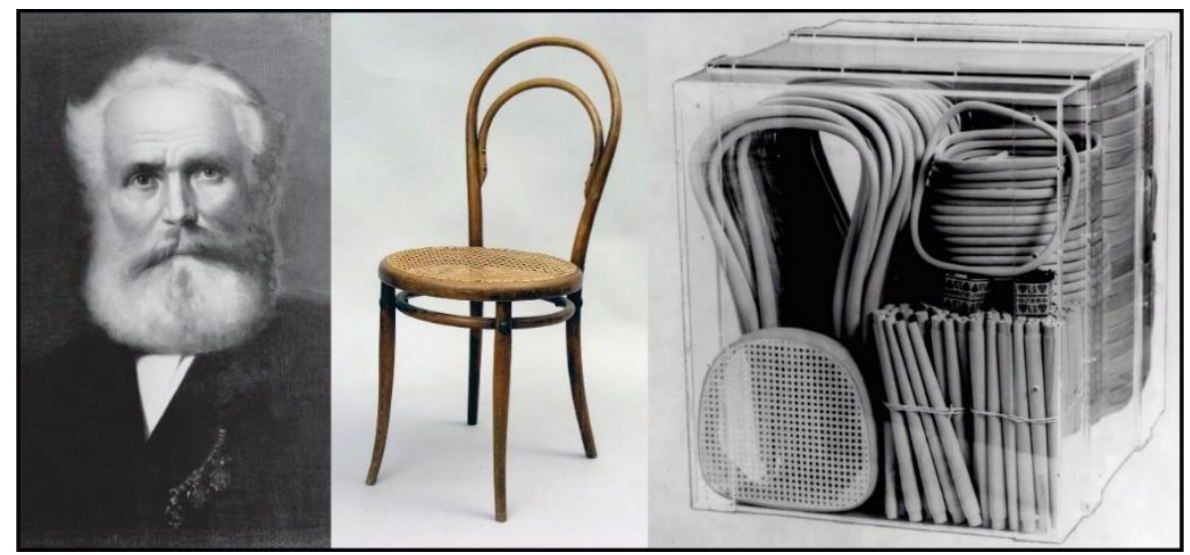

Fonte: http://en.thonet.de/

Além da importância do trabalho de Thonet para uma cultura do design, com a criação de um processo industrial para a geração de produtos, Thonet foi também conquistou alguns feitos como: 1. Eficiência no processo produtivo, diminuindo etapas de produção; 2. Uma redução considerável no número de componentes necessários para a produção da cadeira; 3 . Revolucionário processo de embalagem da cadeira desmontada, para o transporte de longas distâncias, cabendo 36 unidades completas da cadeira no 14 em cada volume; 4. Uma ampla rede de distribuição com lojas em várias capitais ao redor do mundo. Além de poder ser considerado um extraordinário designer, empresário e inventor, Thonet era possuidor de uma visão ampla e muito hábil homem de negócios, característica perceptível ao se analisar sua rápida resposta às reclamações recebidas sobre suas cadeiras, em países tropicais, onde o calor e a umidade excessivos afetavam o seu processo de torção: rapidamente Thonet buscou uma solução, desenvolvendo um processo de moldar a madeira a vapor, resolvendo o problema em questão. A cadeira Thonet tornou-se um ícone do design de produto. A empresa, existente até os dias atuais, continua a produzir e comercializar 
o mesmo produto 5 .

\section{Qual a importância dos movimentos culturais neste contexto?}

A partir de 1890 surge o movimento conhecido como art nouveau, que teve seu berço na França, mas em pouco tempo se expandiu para todo território europeu. Sua essência estava intimamente ligada às correntes artísticas que emergiam no final do século XVIII, início do século XIX aflorando a imaginação, propiciando maior simbolismo nas artes. Por outro lado, a produção industrial ganhava evidência com a forma de utilização de novos e modernos materiais, como cimento, ferro e vidro. Diferente do movimento Arts \& Crafts, o movimento Art Nouveau enfatizava a ciência e as engenharias, que por sua vez, acompanhavam a ascensão da classe burguesa. Podese considerar o movimento Art Nouveau como um dos primeiros fenômenos de moda (entendida aqui como uma novidade que toma conta de todos os aspectos da vida), onde as tendências surgidas da arte eram aplicadas aos artefatos. Considera-se o movimento Arts \& Crafts como uma aglomeração de pensamentos, ideias e ideais não apenas de artistas, arquitetos e designers de vários países, mas também de críticos e da opinião pública, que deu origem a uma série de artefatos, como mobiliários, joias, pinturas, materiais gráficos, edifícios, obras urbanas entre outros. Pevsner (2001), fala que o movimento art nouveau salta a linha divisória entre os dois séculos, e sua significação histórica repousa nas inovações que se voltam para o futuro, elas são a recusa a continuar com o historicismo do século XIX, a coragem de acreditar na própria inventividade, a preocupação com objetos de uso no lugar de pinturas e estátuas.

Um exemplo da influência do movimento art nouveau nos artefatos produzidos nesta época e que, em um primeiro momento encantou a classe burguesa, foi a máquina de costura da marca Singer (FIG. 3), um dos produtos mais vendidos na história do comércio de máquinas, em que é possível verificar a preocupação era com os sentidos produzidos acerca da estética e tecnológia. 0 projeto desta máquina priorizou formas e ornamentos da natureza, provavelmente para contrastar com a frieza do ferro e dos acessórios da máquina. Pode-se entender esse uso do ornamento como uma evidência da atribuição de signos, que representavam uma ideologia, aos artefatos.

Figura 3 - Primeiras máquinas de costura Singer

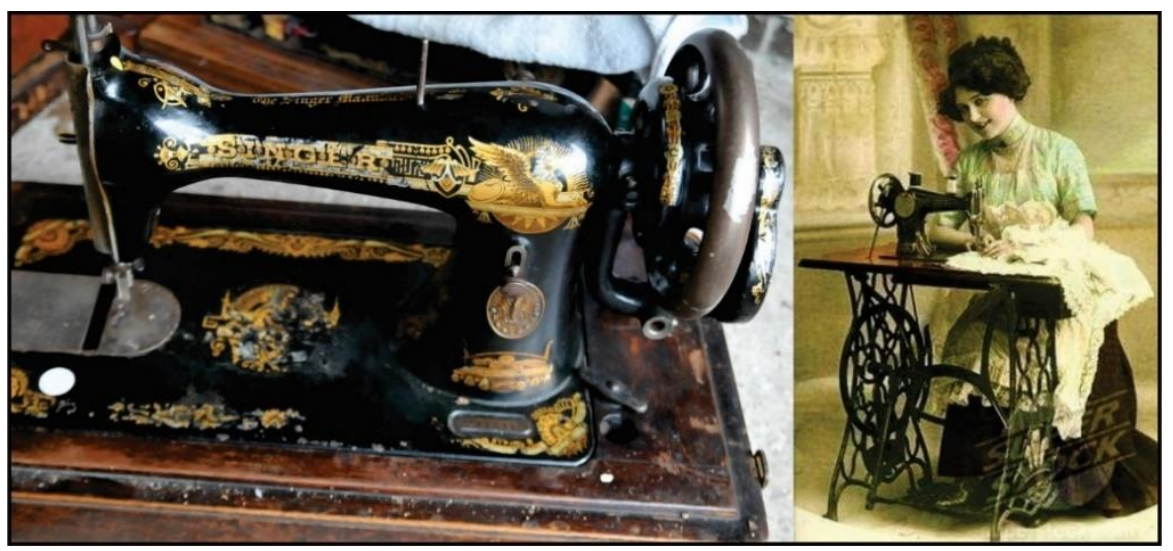

Fonte: ttp://www.singer.com.br/nossa-historia/

Considera-se como características de estilo deste movimento: a aparição de desenhos

\footnotetext{
${ }^{5}$ Disponível em: <http://tipografos.net/designers/thonet.html>
} 
arabescos, com uso de padrões florais; formas orgânicas e geométricas; uma possível referência à união entre a natureza e a técnica; cores sólidas e pasteis; o uso de figuras femininas, dentre outros.

Ao analisar este contexto, arrisca-se dizer que o movimento art nouveau pode ter sido um precursor do que hoje é conhecido como mimética ${ }^{6}$, um estudo mais recente que ampliou as possibilidades do design. De certa forma, os produtos (artefatos) representam as percepções (através de signos) que temos do mundo a nossa volta: desenvolvimentos tecnológicos, valores estéticos, éticos e morais, que nos propicia interpretar ou reinterpretar a cultura na qual nós estamos inseridos (THOMPSON, 2011).

Entre o final do século XIX e início do século XX, diversos acontecimentos sociais e econômicos impactaram no desenvolvimento do design em várias partes do mundo. De vários locais surgiam reações contrários à ornamentação dos produtos e o seu vínculo com estilos artísticos. Na procura por uma formalidade estética e um pensamento lógico que mais se adequasse aos aspectos tecnológicos do mundo moderno, muitos profissionais que lidavam com o design, direcionaram seu foco para instrumentos, máquinas e produtos da indústria, considerando estes exemplos como referência a seguir. A indústria buscava desenvolver e produzir artefatos que esteticamente estavam relacionados aos gostos das classes mais abastadas, aumentando as chances de aprovação. Na sequência, as tendências eram copiadas pelas classes menos providas de recursos (FORTY, 2007).

$\mathrm{Na}$ história da humanidade, os objetos sempre foram portadores de significados culturais e sociais, representativos de uma variedade enorme de estilos de vida, seja de forma intencional ou não, ou ainda na passagem do tempo, com a mudança dos significados existentes nos objetos em relação ao observador. De certa forma, o capitalismo potencializou essa característica ao elevar os objetos à categoria de objetos de consumo, enfatizando o valor da troca com o entendimento do valor agregado. Ainda que este objeto mantenha seu sentido básico, ou seja, aquilo que ele mostra ser ou fazer, a leitura das pessoas percebe um novo valor, o valor trazido por signos que não dizem respeito somente a utilidade do objeto, mas a valores que podem ser incrementados no objeto, remetendo ao conceito de valor agregado (FORTY, 2007).

Mas mesmo que este processo de mudanças no objeto de design tenha muitas transformações relevantes ocorridas no século XIX, foi no século XX, mais precisamente em 1919 quando o sonho do alemão Walter Gropius deu origem ao surgimento da escola Bauhaus, é que acontece uma revolução do objeto, em que é possível perceber mais nitidamente a acepção da palavra artefato (repleto de intencionalidade humana) para o design, contribuindo com o desenvolvimento da cultura ocidental. A partir deste momento, cheio de especificidade, que o ambiente projetual se define com uso de racionalidade e significação, apresentando um quadro distintivo entre forma e função, o belo e o útil, a arte e a técnica, direcionando ao significado de perfeição funcional. Tudo que foi estudado, criado e produzido na Bauhaus influenciou a estética que é conhecida e admirada até hoje, que propôs uma visão do designer como alguém que vai além do papel de projetista, sendo responsável pelo projeto em várias as escalas humanas: estéticas, sociais, culturais e antropológicas, o que tornou a Bauhaus uma instituição mundialmente representativa de uma cultura própria do design, estruturada para reproduzir e disseminar uma comunicação em massa repleta de formas simbólicas.

Para Cardoso (2013, p.34) “quando se compreende a lógica segundo a qual as formas são

\footnotetext{
${ }^{6}$ Derivada da palavra mimese que significa imitação. Neste contexto, representa um processo dentro do design, que suscita o desenvolvimento de algo, que normalmente imita a natureza.
} 
constituídas, compreende-se também que elas são passíveis de mudança e de adquirirem novos significados".

Os artefatos que foram criados e produzidos a partir da Bauhaus, por diversos profissionais imbuídos desta mesma corrente de pensamento, foram interpretados e reinterpretados pela sociedade, servindo como matriz para a reprodução de artefatos com novos signos presentes em várias culturas até os dias atuais (DROSTE, 2006).

Mas é preciso considerar algumas críticas na construção dessa historiografia do design, como atenta Forty (2007). Essa historiografia acaba sendo centrada principalmente na investigação de trajetórias individuais dos profissionais, que se mantém como uma forte tendência de análise ainda atualmente. Essa ênfase que se foca no designer - a pessoa - exclui considerações que precisam ser analisadas.

Para Forty (2007), o design não evolui de forma natural, mas é elaborado social e culturalmente. Muitos são os fatores e questões no design dos objetos, que passam pela sua utilização, relação com o mercado, o trajeto da produção aos usuários, mas passam também pelos valores, mitos e projeções sociais, sejam elas individuais ou coletivas.

\section{Considerações finais}

Neste artigo, buscou-se fazer um resumo de estudo articulando momentos do percurso sócio-histórico e ideias de autores que fazem um resgate histórico para a construção de uma cultura do design dentro de um período pré-estabelecido.

É importante compreender que, pela própria natureza estrutural do design, a compreensão dos processos evolutivos da sua cultura material, pode ser resgatada pelos indícios contidos nos signos dos artefatos, em relação com outras características sociais da época em que é analisado.

É notável perceber a importância dos estudos sobre a cultura, a partir da definição do conceito de cultura, e entendendo este fenômeno sendo perpassado por emaranhados de significados socialmente elaborados e reproduzidos nos objetos de cada época.

A partir da relação entre a produção de objetos e a cultura em que estão inseridos, podemos perceber que grande parte da bibliografia aponta para uma elaboração histórica do ponto de vista do design europeu, devido à relativamente grande documentação e a disseminação de traços culturais que se espalharam, principalmente pelo mundo ocidental.

Passando da produção têxtil, pelas primeiras máquinas industriais, o desenvolvimento e divulgação do conhecimento científico, do desenvolvimento de técnicas de produção e até de relação com o mercado, pode-se perceber a dinâmica das influências com outros contextos culturais da sociedade, principalmente os movimentos artísticos, que ora são tomados como referência num primeiro momento no desenvolvimento de objetos do design, e em outro momento haver a ruptura, quando se pretende mudar o paradigma social adotado na construção dos conceitos e valores que serão imbuídos nos objetos, como na inversão da dicotomia existente na época (forma e função) promovida pela Bauhaus, definindo um importante momento na história do design, em que as formas simbólicas tem relevância na disseminação massificada de valores e significados.

É notória a relevância de trajetórias particulares de grandes nomes que contribuíram no desenvolvimento de técnicas e ideias que transformaram-se com o passar do tempo até chegarmos 
nos conceitos relacionados às práticas projetuais atualmente aplicadas.

No entanto, é preciso considerar algumas críticas na construção dessa historiografia do design, como seu caráter personalista que tem foco no profissional, deixando de lado considerações que poderiam contribuir com a construção de uma narrativa mais ampla, com outras considerações e pontos de vista.

O design é elaborado social e culturalmente, sendo muitos os fatores que contribuem com sua construção, desde o uso, mercado, o percurso do artefato, além dos mitos e projeções coletivas e individuais sobre este artefato.

\section{Referências}

ASHTON, Thomas Southcliffe. A revolução industrial. Lisboa: Europa América, 1977.

ARGAN, Giulio C. História da arte como história da cidade. São Paulo: Martins, 2014.

BAUDRILLARD, Jean. O sistema dos objetos. São Paulo: Perspectiva, 2006.

BONSIEPE, Gui. Design, cultura e sociedade. São Paulo: Blucher, 2011.

BURDEK, Bernhard E. História, teoria e prática do design de produtos. Tradução Freddy Van Camp. São Paulo: Edgard Blucher, 2006.

CARDOSO, Rafael. Design para um mundo complexo. São Paulo: Cosac Naify, 2013.

DROSTE, Magdalena. Bauhaus 1919 - 1933. Berlin: Taschen, 2006.

FORTY, Adrian. Objeto de desejo: design e sociedade desde 1750. São Paulo: Cosac Naify, 2007.

GEERTZ, Clifford. A interpretação das culturas. Rio de Janeiro: LTC, 2008.

HOBSBAWM, Eric. A era do capital: 1848-1875. Rio de Janeiro: Paz e Terra, 2016.

LARAIA, Roque de Barros. Um conceito antropológico. Rio de Janeiro: Jorge Zahar, 2001.

MOLES, Abraham. Teoria dos objetos. Rio de Janeiro: Tempo Brasileiro, 1981.

PEVSNER, Nikolaus. Origens da arquitetura moderna e do design. São Paulo: Martins Fontes, 2001.

THOMPSON, John B. Ideologia e cultura moderna: teoria social crítica na era dos meios de comunicação de massa. Petrópolis: Vozes, 2011.

VERGANTI, Roberto. Design-driven innovation: mudando as regras da competição - a inovação radical do significado de produtos. São Paulo: Canal Certo, 2012.

ZURLO, Francesco. Entrevista. São Leopoldo, 2006. Disponível em: <http://www.ihuonline.unisinos. br/>. Acesso em: 08 jan. 2018. 